\title{
The chromosomes of the carp, Cyprinus carpio, including those of some related species of Cyprinidae for comparison ${ }^{1)}$
}

By

\section{Sajiro Maxino}

Zoological Institute, Faculty of Science, Hokkaido Imperial University

(With 22 text-figures)

Keccivied Seftemtler 30,1938

The carp, Cyprinus carpio L., belonging to the family Cyprinidae, is a common fresh-water teleost which has a world-wide distribution. In Japan this carp abundantly inhabits almost every river, lake and pond. It is highly valued as one of the food-fishes found in fresh waters of our country, specially in the mountainous regions far from the sea and is also largely domesticated in small ponds for food. Of late years the cultivation of the carp has attracted much attention and has become of great economic importance. The carp in Japan has been subjected to a large number of breeding experiments and genetical studies by Matsui ('30, '36a,b) from the economic standpoint. In view of these facts a karyological study of several closely allied species of the carp is of much importance.

A preliminary report on the chromosomes of the carp was given by the author at the 6th Annual Meeting of the Genetic Society of Japan, Hirosima, 1933 (cf. Makino '34). In the present paper a detailed account of the chromosomes of the same species is given with data obtained from some other forms of Cyprinidae by way of comparison.

The author wishes to offer his cordial thanks to Prof. K. Oguma under whose expert guidance and kind encouragement the work has been carried out. He also feels greatly indebted to Dr. Y. Matsui, of the Piscicultural Branch of the Imperial Fisheries Experiment Station, Toyohasi, who very kindly placed at the disposal of the author all the necessary facilities in his laboratory. This investigation was partly aided by a grant from the "Nippon GakuzyutuSinkokwai" which is gratefully acknowledged here.

1) Contribution No. 131 from the Zoological Institute, Faculty of Science, Hokkaido Imperial University, Sapporo, Japan. 


\section{Material and Method}

Most of the carps (Cyprinus carpio L.) employed here were derived from the stocks of Dr. Y. Matsui, on which his genetical studies have been carried out, and some were obtained from the nursery of our University through the courtesy of Dr. T. Fujita, the former professor of the School of Fishery. Specimens killed in October and November were found to be more favourable for study. Of other species used for comparison, Acheilognathus lanceolatus (Temminck \& Schlegel) and Pseudorasbora parva (Temminck \& Schlegel) were collected in February from the streams adjoining the suburbs of Tokyo with the kind cooperation of Mr. I. Matsui, of the Imperial Fisheries Institute, Tokyo. Tribolodon hakuensis (Günther), on the other hand, was obtained in May from a stream in the vicinity of Sapporo, through the kind offices of Prof. T. Inukai. The author finds it his pleasant duty to acknowledge here the hearty cooperation of all those gentlemen who have so generously helped him in obtaining the material.

In every case, testes were removed in the living condition, cut into small pieces and quickly put into fixatives. The preparations made by the usual paraffin-method from the testes fixed in Champy's solution and Champy-Nakamura's fluid, and stained with Heidenhain's iron-haematoxylin were exclusively used for the investigation. ${ }^{1)}$

The drawings were made with the aid of a camera lucida, using a Zeiss $1.5 \mathrm{~mm}$ apochr. objective and $\mathrm{K} 30 \times$ comp. eyepiece, the scale of magnification being given for each figure.

\section{Observations}

\section{Chromosomes of Cyprinus carpio $\mathrm{L}$.}

The observations on chromosomes recorded here were made chiefly on the common black carp. In domestication, however, some varieties of carp derived from the black carp have been known, such as the 'leather carp' which is scaleless, and 'mirrow-carp', which has rows of large scales along its lateral lines or on the bases of its fins only. The chromosomes of these varieties were also studied by way of comparison, and it will appear from the following description that no chromosomal aberration was ever seen in the material derived from these species. The chromosomes of the gold carp have not yet been investigated.

1) The methods in detail have been given in Makino, S.-The chromosomes of Cryptobranchus allegheniensis. J. Morph., 58, p. 573, 1935. 
The unusually high number of chromosomes in the carp coupled with its cell size of extreme smallness, makes the counting and the determination of the chromosome number very difficult. For this reason the determination of the diploid number is made in the primary spermatogonia which are of a larger size. Fortunately a huge spermatogonium showing a complete set of chromosomes at metaphase was found in a section (Textfigs. 1-2). This is a primordial spermatogonium and it seems to correspond to the residual
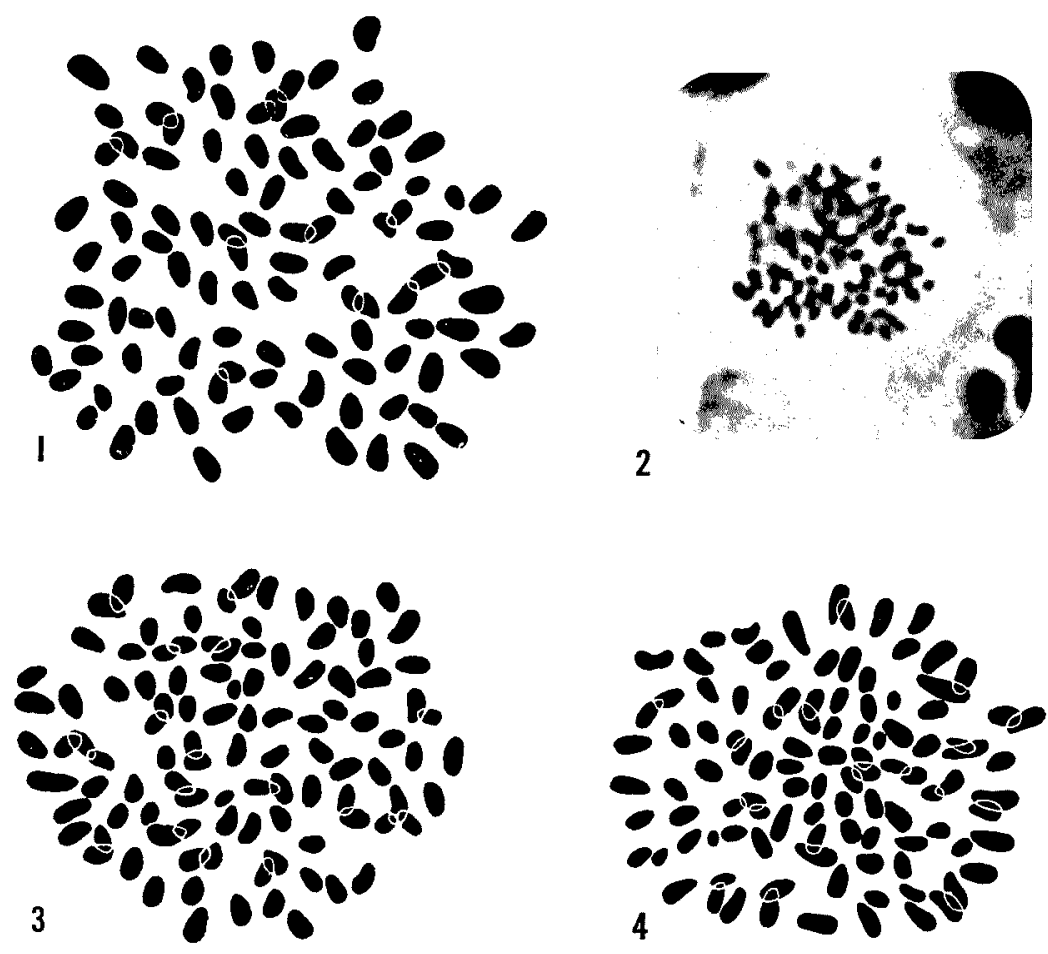

Higs. 1-4. Spermatogonial chromosomes of Cyprinus carpio. 1, leather-carp. 2, photomicrograph of the preparation from which Fig. 1 was drawn. $\times 1900$. 3 , mirrow-carp. 4, common black carp. $\times 5500$.

spermatogonium of Bennington ('36). After a very careful examination of this spermatogonium it was decided without the slightest doubt that the number of chromosomes obtained in it was 104. Two other equatorial plates of the early spermatogonia, which seem to be the descendants of the former kind of cells, as they are smaller in size, were examined, and the same number 104, was determined with certainty (Textfigs. 3-4). In the latter case, however, the counting of the number is rather difficult as compared with the former, because the chromosomes in these smaller cells generally lie with their 
long axis oblique to the radius of the equatorial plate giving rise to some complicated anastomoses. This is due to the fact that the area of the equatorial plate in these cells is too narrow to make all the chromosomes lie evenly scattered.

The diploid complex of the carp chromosome is typically isomorphic, every element appearing as a uniform, short and thick rod-shaped structure with a slight variation in size. They are arranged on the equatorial plate in a radial manner, their tapering ends pointing towards the centre of the equatorial plate.

No numerical and morphological differences were discernible among the chromosome complexes of the varieties of the carp here investigated. The annexed figures bear witness to this fact (Textfig. 1 from the leather-carp, Textfig. 3 from the mirrow-carp and Textfig. 4 from the common black carp).

The tetrads appearing at the metaphase of the primary spermatocytes lie well apart and are distinct enough to enable one to determine their number with certainty. They are evenly distributed on the equatorial plate and maintain their position at regular and constant interval from one another. ${ }^{1)}$ The reduced number of chromosomes in the primary spermatocyte is found to be 52 , the number expected from that which has been observed in the spermatogonium (Textfigs. $5-8$ ). In a lateral view of the metaphase spindle it is revealed that the tetrads are elongated and dumb-bell shaped irrespective of their size, lying with their long axes parallel to that of the spindle, each showing a constriction in its middle portion, or a configuration somewhat knee shaped, gently bent at its middle. In their polar aspect, therefore, the tetrads look rounded or somewhat elongated in outline; or, they may appear as thick, short, rod-shaped structures. Among the bivalents lying in the outer zone of the spindle, there are sometimes found single $V$-shaped tetrads, or thick, triangular ones, which may, as it seems to the author, be the knee-shaped tetrads displaced from their natural position, now lying horizontally on the equatorial plate, with their long axes parallel or situated

1) In poorly fixed material the chromosomes are not regularly oriented in one plane, but lie unevenly scattered without any constant intervals among them. Sometimes there are seen chromatic bridges between chromosomes and frequently certain chromosomes get abnormally protruded from the equatorial plate. Such questionable figures are often encountered in the papers by some authors. The chromosomes regarded by them as XY- or XX-chromosomes in the first division of certain species of fishes at least, for instance, Vaupel ('29) in Lebistes, Ralston ('34) in Xiphophorus and Platypoecilus and Bennington ('36) in Betta, are no other than abnormally protruding ordinary tetrads of this kind. Before making any conclusive statements, it is desirable, that one should bear in mind the fact that such aberrations are likely to be caused by imperfect fixation. 
obliquely to the latter. Every tetrad is composed of two identical components so far as the shape of the two components constituting a bivalent admits of study, and this naturally suggests the fact that there occurs among them no particular chromosome heteromorphic in nature.
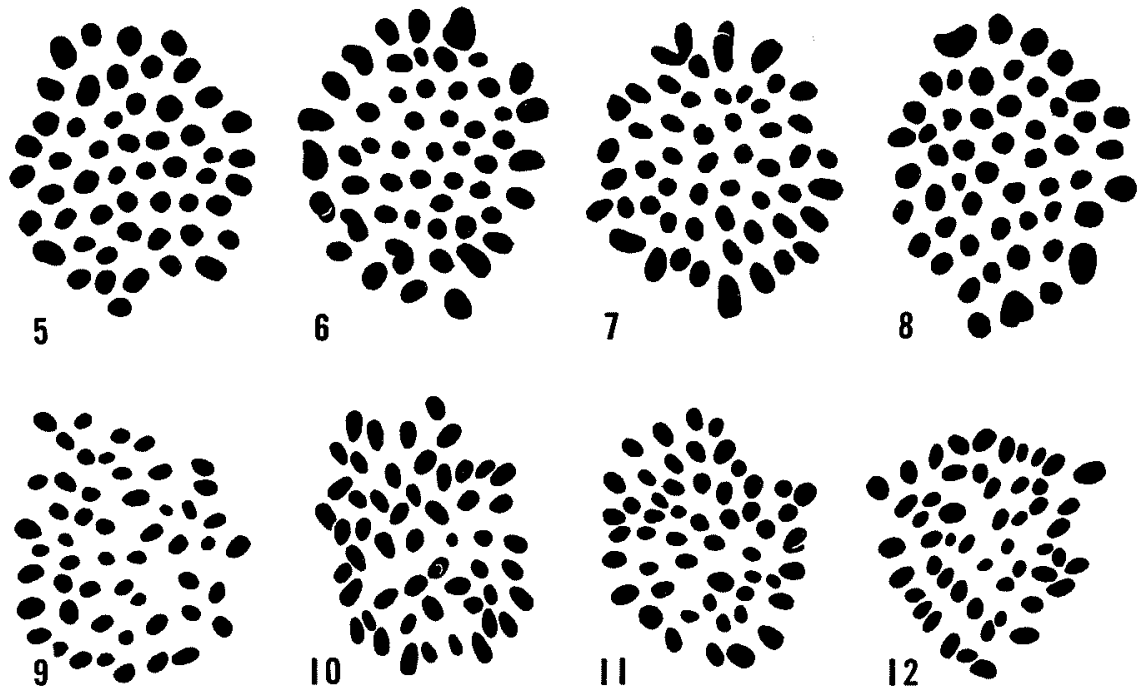

Figs. 5-12. Chromosomes of Cyprinus carpio. 5-8, primary spermatocyte. 5 and 8, leather-carp; 6 and 7 , common black carp. 9-12, secondary spermatocyte, common black carp. $\times 5500$.

The same haploid number, 52, was also established for the secondary spermatocyte (Figs. 9-12). The chromosomes are all thick, short, rod-shape quite in correspondance to those found in the spermatogonium and arrange themselves on the equatorial plate in a radial manner their tapering ends directed towards the centre of the latter. The very minute size of the individual chromosomes in this generation of germ-cells does not admit of further observations.

The chromosome number, $104(2 n)$, established here for the carp is the highest one so far known for any vertebrate. This number was also recorded recently for a species of the Elasmobranch fish, Raja mecidervoortii, in which, however, the chromosomes are different from the present ones in their complement and are highly polymorphic in nature (cf. Makino '37).

2. Chromosomes of Acheilognathus lanceolatus, Pseudorasbora parva and Tribolodon hakuensis.

Acheilognathus lanceolatus, Pseudorasbora parva and Tribolodon hakuensis now to be dealt with are small teleosts, common to the 
streams and rivers, the two former inhabiting waters of the southern parts of Japan. They too belong to the family Cyprinidae.

The primary spermatocyte metaphase was first observed in $A$. lanceolatus and the author was surprised at finding a lower number of chromosomes than that obtained in the carp, 25 being its reduced number (Textfigs. 13-14). The individual tetrads are apparently bigger than those found in the carp. Among the larger tetrads occupying the peripheral zone of the equatorial plate, are found 2 thick V-shaped elements which, as their shape suggests, are atelomitic in their fibre attachment. The distinctly $\mathrm{V}$-shaped dyads are also found in the secondary spermatocytes along with the remaining 23 rod-shaped ones (Textfig. 15). These facts strongly suggest the occurrence of at least two pairs of atelomitic univalent chromosomes in the diploid complement. In fact, an examination of the spermatogonium revealed that the diploid complement consists of 50 chromosomes of various size and shape, the majority of which are rod-shape tapering towards their ends, and varying in shape from straight long rods to thick short ones, while at least 4 chromosomes (in 2 pairs) among these assume a V-shape (Textfig. 16), and this fact is borne out by observations on the primary spermatocyte. One pair of these $V$-shaped elements shows a median attachment constriction, while the other pair is submedian in constriction.

In Pseudorasbora parva the number and the general morphology of the chromosomes closely correspond with those observed in the previous species, $A$. lanceolatus. The chromosomes are 50 in number for the diploid complement (in the spermatogonium; Textfig. 17) and 25 for the haploid (in the primary spermatocyte; Textfigs. 1819). At least 4 univalents in the diploid garniture (or 2 bivalents in the haploid complex) are provided with atelomitic fibre attachment and the remaining ones seem to be telomitic in nature, appearing as rod-shape structures varying in length (Textfig. 17). Here, however, it is noteworthy that the chromosomes of this species are all much condensed as compared with those of the previous species and perhaps because of this fact 2 pairs of atelomitic chromosomes cannot be easily identified and picked out from others in the complex, since every one of the elements has a subterminal fibre attachment, assumes a J-shape and all are of nearly equal size. Because of these characteristics the chromosomal complexes of the two species above mentioned may to some extent be distinguished from one another (cf. Textfigs. 16 and 17).

In Tribolodon hakuensis, the number of chromosomes is in close agreement with those of the previous species, $A$. lanceolatus and 


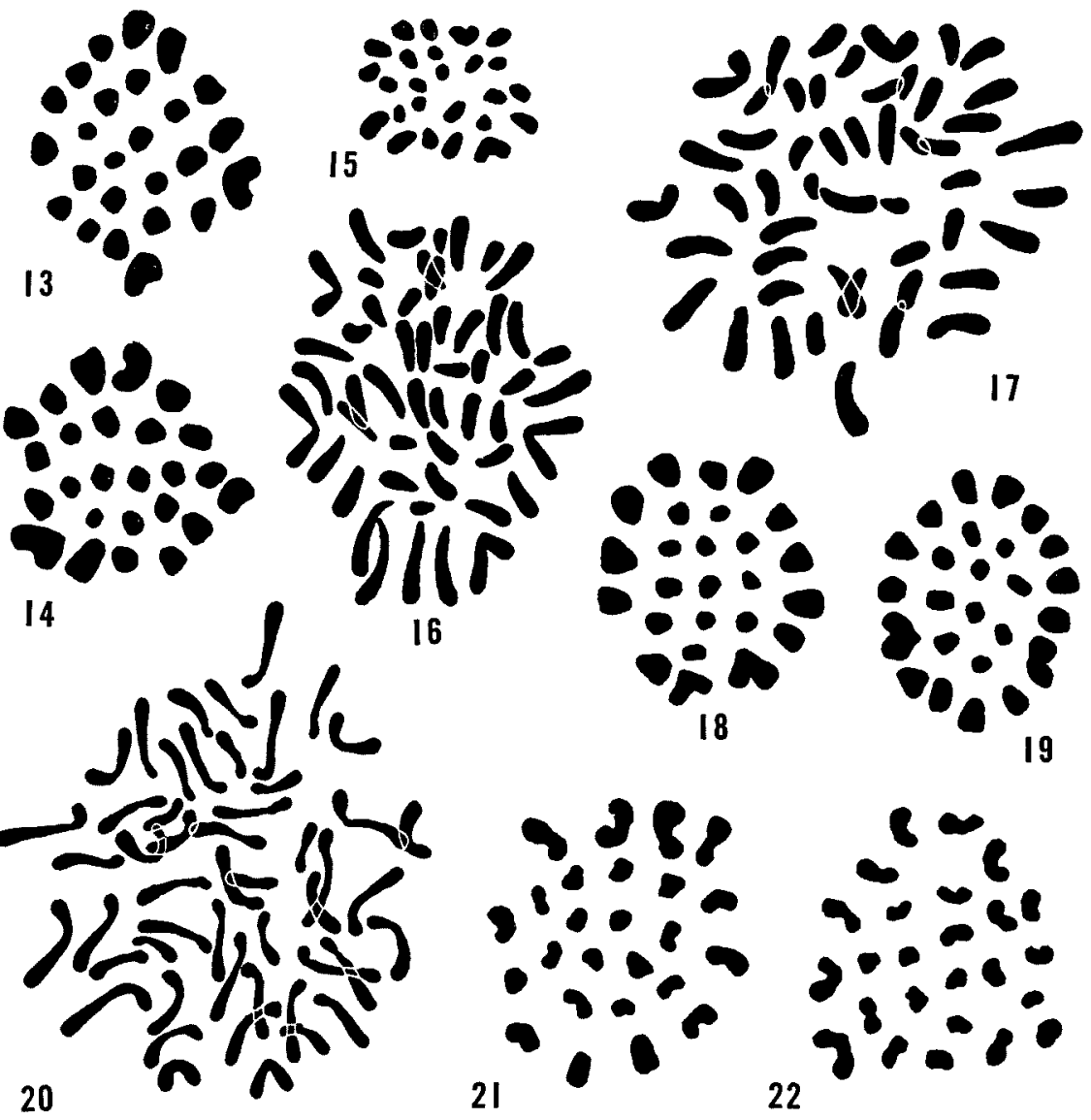

Figs. 13-16. Chromosomes of Acheilognathus lanceolatus. $\times 5500 . \quad 13-14$, primary spermatocytes. 15, secondary spermatocyte. 16, spermatogonium. Figs. 17-19. Chromosomes of Pseudorasbora parva. $\times 5500$. 17, spermatogonium. 18-19, primary spermatocytes. Figs. 20-22. Chromosomes of Tribolodon hakuensis. $\times 5500$. 20, spermatogonium. 21-22, primary spermatocytes.

P. parva, being $\mathbf{5 0}$ for the diploid (Textfig. 20) and 25 for the haploid (Textfigs. 21-22). However, in respect of the chromosomal constitution the present species is strikingly different from the above mentioned two species and also from the carp. As seen in Textfig. 20 , almost every chromosome of the diploid complement shows a conspicuous constriction and, in striking contrast to the common occurrence in teleosts, there is found no rod-chromosome with a tapering end. The majority of the chromosomes, excepting 6 chromosomes (in 3 pairs), which distinctly assume a submedian or median constriction and appear as Vs, have a constriction near one of their extremities, and at the point of constriction they bend to give rise to a shape very much like $J$ or completely like $J$ according to the 
position of the constriction. They show a graduated reduction in length, and with few exceptions they dispose themselves in the equatorial arrangement in such a way that their bent points are directed towards the centre of the equatorial plate. Though it cannot be stated with certainty, nevertheless if we bear in mind the fact that the locus of the spindle fibre attachment lies at region of constriction, all these chromosomes should be regarded as atelomitic chromosomes with subterminal, submedian or median attachment. The morphological condition of the tetrads as observed in the primary spermatocyte metaphase seems to vindicate this view to some extent, since they structurally suggest themselves to be provided with atelomitic fibre attachment excepting some small ambiguous ones (cf. Textfigs. 21-22).

\section{Comparison of the chromosomes}

Exact knowledge has been meagre on the chromosomes of the Pisces of any group (cf. Oguma \& Makino '37). Of the family Cyprinidae, no species was ever before cytologically studied barring two fragmentary notes published on Cyprinus and Carassius by the present author ('34, '35).

The findings of the present investigation reveal that each species has its own specific karyotype, different from the other irrespective of the fact that whether any two species are closely related or not from the systematic point of view. Nor have we discovered any common characteristics among their chromosomal complexes.

Acheilognathus and Pseudorasbora form the only instance where the similarity observed between their chromosomal complexes would justify our regarding these chromosomal garnitures as belonging to one and the same category. Cyprinus carpio, in the first place, is quite unique in having an isomorphic complex which is composed of 104 chromosomes all of which are thick, short rod-shaped elements with tapering ends without any marked size differences among themselves. No comparable case is so far known not only among fishes but in other vertebrates as well. One can find, however, some resemblance between such a kind of karyotype and chromosomal complexes of some Lepidopteran insects and decapod Crustaceans. Closely allied to Cyprinus is Carassius carassius ${ }^{1)}$ in which, in contrast to the kinship existing between them, their karyotypes are quite dissimilar both in the number and shape of chromosomes contained in their respective complexes (cf. Makino '34, '35) ${ }^{2)}$ Carassius

1) According to Tanaka ('28), this scientific name should be applied to both, the gold-fish and its wild form 'Funa'.

2) Detailed study is in progress for various varieties of the gold-fish. 
possesses 94 chromosomes (in $2 n$ ), which, in striking contrast to those of Cyprinus above mentioned, are elongated, rod-shaped elements varying in length. The male specimens of $F_{1}$ hybrids between Cyprinus and Carassius obtained in the experiments of Matsui ('33) have proved to be sterile, as they produce no spermatozoa. Cytological observations on these hybrid testes show that some abnormalities occur in the maturation phenomena, which are probably caused by the failure of conjugation between chromosomes derived from the two parents. The morphological differences in number and shape of chromosomes occurring between the parents, are quite suggestive of this failure of conjugation in the meiosis of the hybrid. This problem will be dealt with in another paper.

The chromosome complex of Acheilognathus lanceolatus and that of Pseudorasbora parva show a remarkable characteristic in the presence of at least 2 pairs of V-shaped chromosomes, which stand out in striking contrast to the remaining 46 rod-shaped elements in each garniture. Such a complement has never been recorded before in any species of fishes. However, in respect of the number of chromosomes these two above mentioned species seem to be nearly related to the Cobitidae, a group allied to Cyprinidae, since in a species of Cobitidae, Misgurnus anguillicaudatus, the author has reported 52 (in $2 n$ ), elongated, rod-shaped chromosomes (Makino '37).

The chromosomes of Tribolodon hakuensis are peculiar in that some of them have a median constriction, while others show subterminal and terminal constrictions which are constant for every chromosome. Most of them assume terminal and subterminal constrictions where they are found more or less bending. These peculiarities, therefore, confer on them a distinction all their own, by virtue of which they can be quite clearly differentiated from the usual rod-shaped elements with tapering ends. Though it is not certain whether the spindle fibre gets attached to the constricted region in the case of every chromosome, it is noteworthy that the chromosome complex of this kind has never been recorded for any other form among the lower vertebrates. The metaphase garniture of this species at the first sight under the microscope shows a remarkable resemblance to that of some mammalian species which, though apparent, is none the less striking.

Upon reviewing the literature on the piscian chromosomes it was discovered that several other kinds of karyotype, different from those above noted occur in teleost fishes. The most common one, which is widely found in the majority of species investigated, seems to be a complement in which all the elements assume a rod-shape, 
but they vary in length. All the members of Cyprinodontidae which have been so far studied cytologically, namely, Aplocheilus (Iriki '32), Lebistes (Winge '23; Vaupel '29; Iriki '32), Xiphophorus, Platypoecilus (Ralston '34; Friedman \& Gordon '34) and Gambusia (Geiser '24) all possess this kind of karyotype. Carassius of Cyprinidae (Makino '34, '35), Misgurnus of Cobitidae (Makino '37), Pungitius of Gasterosteidae (Makino '34), Betta of Osphromenidae (Bennington '36) and Pholis of Pholidae (Makino '37), all furnish examples of a karyotype similar to the above. A peculiar type has been found in a species of the Esocidae, Umbra limi in which Foley ('26) discovered 22 chromosomes, all elements being V-shape. Recently a very complicated garniture which is a combination of atelomitic and telomitic elements of various shapes, was recorded for several species of Salmonidae (Prokofieva '34; Makino '37). In the Elasmobranch fishes, on the other hand, the investigations carried out by the present author reveal two quite complicated karyotypes, one for Raja (the skate) and the other for Squalus (the shark), which materially differ from each other in several respects. The former species has 104 chromosomes which are rod and spherular shaped elements, while the latter possesses 62 chromosomes composed of several types of atelomitic and telomitic elements (Makino '37). The evidence presented here, therefore, suggests that the chromosomes of the Pisces do not conform to a common type, and that many different kinds of karyotypes prevail in this group. This remarkable diversity, or, rather, paucity of common features among the chromosomal complexes of various groups of fishes may presumably correspond to the complexity that is experienced in classifying these aquatic vertebrates.

\section{Literature}

Bennington, N. L. 1936. Germ cell origin and spermatogenesis in the Siamese fighting fish, Betla splendens. Journ. Morph., 60, p. 103.

Foley, J. O. 1926. The spermatogenesis of Umbra limi with special reference to the behaviour of the spermatogonial chromosomes and the first maturation division. Biol. Bull., 50, p. 117.

Friedman, B. and M. Gordon 1934. Chromosome numbers in Xiphophorin fishes. Am. Nat, 68, p. 446.

Geiser, S. W. 1924. Sex ratios and spermatogenesis in the topminnow, Gambusia holbroolci Grd. Biol. Bull., 47, p. 175.

Iriki, Sh. 1932a. Preliminary notes on the chromosomes of Pisces. I. Aplocheilus latipes and Lebistes reticulatus. Proc. Imp. Acad. (Tokyo), 8, p. 262.

- 1932b. Studies on the chromosomes in Pisces. On the chromosomes of Aplocheilus latipes. Sci. Rep. Tokyo Bunrika Daigaku, Sec. B, 1, p. 127.

Makino, S. 1934a. The chromosomes of the sticklebacks, Pungitius tymensis (Nikolsky) and Pungitius pungitius (Linnaeus). Cytologia 5, p. 155.

- 1934b. Notes on the chromosomes of some fresh-water Teleosts (in Japanese). Jap. Journ. Genet., 9, p. 100. 
Makino, S. 1935. A close relationship between ' $F u n a$ ' and gold-fish as seen in the morphology of the chromosomes (in Japanese). (Kagaku), 5, p. 56.

- 1937a. Notes on the chromosomes of some teleost fishes. Zool. Mag. (Japan), 49 , p. 75 .

- 1937b. The chromosomes of two Elasmobranch fishes. Cytologia, Fujii Jubilee Volume, p. 867 .

Matsui, Y. 1930. Genetical studies on fresh-water fish. I. On the new mutants in carp (Cyprinus carpio L.). Journ. Imp. Fish. Exp. St., No. 1, p. 167.

- 1931. Genetical studies on fresh-water fish. II. On the hybrids of Cyprinus carpio L. and Carassius carassius (L.). Journ. Imp. Fish. Exp. St., No. 2, p. 129.

- 1932. On the secondary sexual character of carp, Funa and gold-fish; on the sterility of their hybrids (in Japanese). Rep. Japan. Assoc. Adv. Sci., 7.

- 1933. Genetical studies on fresh-water fish. III. On the male sterility of hybrids of Cyprinus carpio L. and Carassius carassius (L.) or its varieties. Journ. Imp. Fish. Exp. St., No. 3, p. 249.

- 1936a. On the genetical experiments in carp (in Japanese). Fishery Investigation (Imp. Fish. Exp. St.), No. 3, p. 48.

- 1936b. On the genetical studies in carp (a preliminary note in Japanese). Jap. Journ. Genet, 12, p. 44.

Oguma, K. and S. Makino 1937. A new list of chromosome numbers in Vertebrata (March 1937). Journ. Fac. Sei., Hokkaido Imp. Univ., Ser. VI, Zool., 5, p. 297.

Prokofieva, A. 1934. On the chromosome morphology of certain Pisces. Cytologia, 5, p. 498.

Ralston, E. M. 1934. A study of the chromosomes of Xiphophorus, Platypoecilus, and of Xiphophorus-Platypoecilus hybrids during spnermatogenesis. Journ. Monph., 56, p. 423.

Tanaka, S. 1928. Fishes of Japan. Vol. 45.

Vaupel, J. 1929. The spermatogenesis of Lebistes reticulatus. Journ. Morph., 47, p. 555 .

Winge, Ö. 1922. A peculiar mode of inheritance and its cytological explanation. Journ. Genet., 12, p. 137. 